\title{
Analysis of the Metrological Reliability - Study on Simulated and Experimental Data
}

\author{
Ramona CLINCIU \\ Transilvania University of Brasov, Romania, r.clinciu@unitbv.ro
}

\begin{abstract}
The paper presents an algorithm for simulation of the parameter deviation. The case of a normal distribution function is considered, due to the fact that normal distribution is met frequently in the reliability analysis. The aim of the simulation of the parameter deviation is represented by the determination of the calibration life of the measuring devices as a function of the metrological reliability, by means of the parameter deviation functions. The algorithm constructed for determining the calibration life based on the parameter deviation was first checked in case of simulated data an then it was used for experimental research. The paper presents also the results of experimental studies conducted on specific mechanical measuring instruments - external micrometers for 25 - 50 $\mathrm{mm}$ and external caliper rules of $150 \mathrm{~mm}$ with depth rod and with a resolution of $0.1 \mathrm{~mm}$. The aim of the study is to determine the calibration life of the considered measuring devices as a function of the metrological reliability, by means of the parameter deviation function and then to compare it with the pre-set calibration life stated in the appropriate standards.
\end{abstract}

Keywords

metrological reliability, parameter deviation, normal distribution

\section{Introduction}

Parameter deviation represents a very useful research tool for the analysis of the metrological reliability since it can be used for estimation of the metrological reliability as well as for the estimation of the calibration life of a certain measuring device.

Any measuring device is characterized by a certain tolerance interval. In case the measuring device is correctly adjusted, then the measurement errors are included in the specified tolerance interval. During the measuring process, the measurement errors modify, they increase and it happens that, at a certain moment, they exceed the tolerance interval. In case the probability density function for the measurement errors exceeds the tolerance interval with a certain percentage, it is considered that a metrological disturbance has appeared. Due to the hidden nature of this metrological disturbance, it cannot be discovered by the time it is produced; it can be discovered only during the periodical checking of the measuring device or by the negative consequences generated by the use of the considered measuring device [1].

Parameter deviation represents a very useful research tool for the estimation of the metrological reliability and for the determination of the calibration life. Given the parameter deviation function, one can predict the moment in time when the probability density function for the measurement errors exceeds the tolerance interval with a certain percentage, corresponding to the chosen level of significance. This moment corresponds to the stage in which the considered measuring device needs to be checked and, if necessary, calibrated $[1,2]$.

The present paper presents an algorithm for simulation of the parameter deviation, for determining the calibration life of the measuring devices as a function of the metrological reliability, by means of the parameter deviation functions. It will present the results obtained in case of simulated data and by this, the algorithm will be checked such as to be used in case of experimental data as well. The paper presents also the results of experimental studies conducted on specific mechanical measuring devices - caliper rules and micrometers, in order to determine the calibration life of the considered measuring devices as a function of the metrological reliability, by means of the parameter deviation function.

The research was conducted on specific measuring instruments - external micrometers for 25 - 50 $\mathrm{mm}$ and external caliper rules of $150 \mathrm{~mm}$, with depth rod, with a resolution of $0.1 \mathrm{~mm}$, the aim of the 
research being the estimation of the calibration life of these measuring instruments. This experimental research may be added to former researches performed on different types of measuring instruments [3, 4], in laboratory conditions.

In the experimental studies conducted on these measuring instruments, the input data is represented by the measuring errors, obtained by measuring the same nominal size, measuring errors that are grouped in samples produced at a specific period of time, by measuring in laboratory conditions the same dimension with a set of measuring instruments of the same type. The contribution of the author in this research is represented by the estimation of the calibration life of the considered measuring instruments, as a function of the metrological reliability, based on the internal parameter deviation and the comparison of this estimated calibration life with that specified in the appropriate standards [5].

\section{Algorithm for Estimating the Calibration Life of the Measuring Instruments}

In general, in metrology it is used especially the normal distribution, although positive and asymmetrical distributions (e.g. Weibull distribution) are frequently met in the analysis of the metrological reliability [6].

The algorithm constructed for estimating the calibration life of the measuring instruments uses the following notations: $\alpha$ - the level of significance; $m$ - the mean; $\sigma$ - the standard deviation; $n$ - the volume of the sample; $k$ - the number of samples; $x_{j i}$ - the experimental data, which is assumed to be normally distributed, according to the normal distribution function $\mathrm{N}(m, \sigma, t)(j=1, \ldots, k, i=1, \ldots, n)$ having both parameters $m$ and $\sigma$ variable; $m_{0}$ - the initial value of the mean; $a$ - the variation coefficient of the mean; $\sigma_{0}$ - the initial value of the standard deviation; $b$ - the variation coefficient of the standard deviation; $T_{\varepsilon}$ - the tolerance interval for variable $\varepsilon$, as a measurement error; $t i$ - the initial moment; $d t$ - the interval between the collection of the samples (it is considered that dt is constant); $t_{r}$ - the calibration life.

The case of a normal distribution $\mathrm{N}\left(m_{0}, \sigma_{0}, t\right)$ is considered. After a period of time, due to the internal parameter deviation, the parameters of the distribution become $m$ and $\sigma$, such as the distribution becomes $\mathrm{N}(m, \sigma, t)$. It is considered that the mean $m$ and the standard deviation $\sigma$ may have a linear or an exponential variation, according to the equations:

$$
\begin{gathered}
m=m_{0}+a \cdot t, \\
\sigma=\sigma_{0}+b \cdot t, \\
m=m_{0} \cdot \exp (a \cdot t), \\
\sigma=\sigma_{0} \cdot \exp (b \cdot t) .
\end{gathered}
$$

The algorithm for estimating the calibration life of the measuring devices as a function of the metrological reliability includes the following steps [2]:

- Data collection - simulated or experimental data collected from field operation;

- Data outlier tests- Grubbs test [7];

- Distribution assumption - normal distribution, as used by general metrology;

- Parameter estimation for the chosen distribution - normal distribution [7];

- Goodness-of-fit tests performance: general goodness-of-fit test (Kolmogorov-Smirnov) and normality goodness-of-fit tests (Lilliefors, Filliben); the optimum distribution is validated by the values of the statistics of the tests considered: $d_{j}$ - the value of the statistics of the KolmogorovSmirnov goodness-of-fit test; $L_{j}$ - the value of the statistics of the Lilliefors goodness-of-fit test [6, 8-11]. These values are compared to the critical values of the tests: $d_{n, \alpha}$ - the critical value of the statistics of the Kolmogorov-Smirnov goodness-of-fit test, $L_{n, \alpha}$ - the critical value of the statistics of the Lilliefors goodness-of-fit test, $r_{n, \alpha}$ - the critical value of the statistics of the Filliben goodness-offit test [8];

- Determining the parameter deviation functions by means of regression analysis $\left(m_{0}^{\prime}, a^{\prime}, \sigma_{0}^{\prime}, b^{\prime}\right.$ - the estimated coefficients of the parameter deviation function) and the correlation coefficients for the linear variation $\left(r_{\mathrm{m}-\mathrm{l}}, r_{\sigma-1}\right)$ and for the exponential variation $\left(r_{\mathrm{m}-\exp }, r_{\sigma-\exp }\right)[7,8]$. The type of the 
parameter deviation function (linear or exponential) for each parameter $-m$ and $\sigma$, is indicated by the highest value of the two calculated correlation coefficients for each parameter $\left(r_{\mathrm{m}-\mathrm{l}}\right.$ or $r_{\mathrm{m} \text {-exp }}$ and $r_{\sigma-1}$ or $r_{\sigma-e x p}$, respectively);

- Determining the calibration life, by means of parameter deviation functions, according to the method described in [2]. The pre-set calibration time for length measuring instruments is set to two years, as stated in the appropriate standards [5].

\section{Case of Simulated Data}

Programmed generation of normally distributed data is achieved according to the relations presented below [7]:

$$
\begin{gathered}
z_{i}=F^{-1}\left(\alpha_{i}\right) ; \\
\alpha_{i}=\frac{i-3 / 8}{n+1 / 4}, \quad i=1, \ldots, n ; \\
F(z)=\frac{1}{2 \cdot \pi} \int_{0}^{z} e^{-\frac{t^{2}}{2}} d t .
\end{gathered}
$$

Table 1 presents the results obtained in case of programmed generation of normally distributed data, data obtained according to (5), where $n=30, k=3, \alpha=0.05, m_{0}=0, a=0.408, \sigma_{0}=1, t i=0, d t=1$, $T_{\varepsilon}=13.082$. In this case the calibration life should be $t_{r}=12$, value which was obtained.

Table 1. Programmed generation of normally distributed data

\begin{tabular}{|c|c|c|c|c|c|c|}
\hline Sample & 1 & 2 & 3 & $L_{j} \leq L_{n, \alpha}=0.161$ for normal distribution \\
\hline \multirow{2}{*}{$L_{j}$} & \multicolumn{7}{|c|}{ Lilliefors Goodness-of-fit Tests } \\
\cline { 2 - 7 } & 0.022 & 0.022 & 0.022 & \multicolumn{2}{c|}{ normal distribution accepted } \\
\hline \multirow{2}{*}{$m$} & 0 & 0.408 & 0.816 & $m_{0}=0$ & $a=0.408$ & $r_{m}=1$ \\
\cline { 2 - 7 } & 0 & 0.9564 & 0.9564 & 0.9564 & $b=0$ & $r_{\sigma}=1$ \\
\hline$\sigma$ & 0.9564 & \multicolumn{7}{|c|}{12} \\
\hline$t_{r}$ & \multicolumn{7}{|c|}{} \\
\hline
\end{tabular}

\section{Estimating the Calibration Life of the Micrometers}

The experimental study is conducted on a set of micrometers for $25-50 \mathrm{~mm}$. Experimental data is represented by the measuring errors, obtained by measuring a certain nominal size. Data is grouped in three samples, each of volume $n=30$, produced at a certain period of time (a month), $d t=1$, by measuring the same dimension with the set of micrometers, in laboratory conditions. The level of significance is $\alpha=0.05$.

Table 2 presents the values of the statistics of both Lilliefors and Filliben goodness-of-fit tests for each sample. These values are according to both conditions: $L_{j} \leq L_{n, \alpha}=0.161$ for Lilliefors goodness-offit test and respectively $r_{j}>r_{n, \alpha}=0.994$ for Filliben goodness-of-fit and this indicates normal

\begin{tabular}{|c|c|c|c|}
\hline Sample & 1 & 2 & 3 \\
\hline \multirow{2}{*}{$\mathrm{L}_{\mathrm{j}}$} & \multicolumn{3}{|c|}{ Lilliefors Goodness-of-fit Tests, $L_{j} \leq L_{n, \alpha}=0.161$ for normal distribution } \\
\hline & 0.0702 & 0.1062 & 0.0845 \\
\hline \multirow[t]{2}{*}{$r_{j}$} & \multicolumn{3}{|c|}{ Filliben Goodness-of-fit Tests, $r_{j}>0.994$ for normal distribution } \\
\hline & 0.9943 & 0.9903 & 0.9915 \\
\hline
\end{tabular}
distributions [6-8].

Table 2. Values of the statistics of the Goodness-of-fit Tests

The values of the estimated parameters $m$ and $\sigma$ for each sample are given in Table 3. 
RECENT, Vol. 22, no. 2(64), 2021

Table 3. Values of the estimated parameters of the samples

\begin{tabular}{|c|c|c|c|}
\hline Sample & 1 & 2 & 3 \\
\hline$m$ & 0.9412 & 1.1592 & 1.9316 \\
\hline$\sigma$ & 0.992 & 0.8962 & 0.7491 \\
\hline
\end{tabular}

By using the values of the means and standard deviations of the samples, presented in Table 3, one can find the parameter deviation functions, by means of regression analysis $[7,8]$. The correlation coefficients for linear variation of the parameters are $r_{m-1}=0.983$ and $r_{\sigma-1}=0.992$ and the correlation coefficients for exponential variation of the parameters are $r_{\mathrm{m} \text {-exp }}=0.8130$ and $r_{\sigma-\exp }=0.9703$; these values indicate a linear variation for both parameters, according to the equations:

$$
\begin{gathered}
m=0.985+0.495 \cdot t ; \\
\sigma=1-0.121 \cdot t .
\end{gathered}
$$

The calibration life, for the considered case, is calculated by means of parameter deviation functions (8) and (9), according to the method described in [2]. The value which is obtained for the calibration time is $t_{r}=16.1032$ time units (months).

\section{Estimating the Calibration Life of the Caliper Rules}

The experimental study conducted is aimed on the estimation of the calibration life of external caliper rules of $150 \mathrm{~mm}$, with depth rod, with a resolution of $0.1 \mathrm{~mm}$. The experimental data is represented by the measuring errors, obtained by measuring the same nominal size with a set of caliper rules and is grouped in samples produced monthly. For the nominal size measured, the tolerance interval is $T_{\varepsilon}=0.16 \mathrm{~mm}$, while the other values are the following: $\alpha=0.05, n=16, k=4, t i=0$ and $d t=1$.

Table 4 presents the values of the statistics of both Kolmogorov-Smirnov and Lilliefors goodness-offit tests for each sample. These values are according to both conditions: $d_{j} \leq d_{n, \alpha}=0.328$, for KolmogorovSmirnov goodness-of-fit test and respectively $L_{j} \leq L_{n, \alpha}=0.213$ for Lilliefors goodness-of-fit and this indicates normal distributions $[6,8,12]$. The values of the estimated parameters $m$ and $\sigma$ for each sample are given in Table 5.

\begin{tabular}{|c|c|c|c|c|}
\hline Sample & 1 & 2 & 3 & 4 \\
\hline \multirow{2}{*}{$d_{j}$} & \multicolumn{4}{|c|}{ Kolmogorov-Smirnov Goodness-of-fit Tests, $d_{j} \leq d_{n, \alpha}=0.328$ for normal distribution } \\
\hline & 0.4839 & 0.3226 & 0.2607 & 0.2455 \\
\hline \multirow{2}{*}{$L_{j}$} & \multicolumn{4}{|c|}{ Lilliefors Goodness-of-fit Tests, $L_{j} \leq L_{n, \alpha}=0.213$ for normal distribution } \\
\hline & 0.4213 & 0.3022 & 0.2392 & 0.1918 \\
\hline
\end{tabular}

Table 4. Values of the statistics of the Goodness-of-fit Tests

Table 5. Values of the estimated parameters of the samples

\begin{tabular}{|c|c|c|c|c|}
\hline Sample & 1 & 2 & 3 & 4 \\
\hline$m$ & -0.0032 & 0.0249 & 0.0013 & 0.0031 \\
\hline$\sigma$ & 0.0068 & 0.0083 & 0.0092 & 0.0093 \\
\hline
\end{tabular}

By using the values of the means and standard deviations of the samples, presented in Table 5, one can find the parameter deviation functions, by means of regression analysis $[6,8]$. The correlation coefficients for linear variation of the parameters are $r_{m-1}=0.8016$ and $r_{\sigma-1}=0.9144$ and the correlation coefficients for exponential variation of the parameters are $r_{\mathrm{m} \text {-exp }}=0.7923$ and $r_{\sigma-\exp }=0.9077$; these values indicate a linear variation for both parameters, according to the equations:

$$
\begin{gathered}
m=-0.0017+0.0016 \cdot t ; \\
\sigma=0.0073+0.0008 \cdot t .
\end{gathered}
$$

The calibration life is calculated by means of parameter deviation functions (10) and (11). The value obtained for the calibration time is $t_{\mathrm{r}}=22.081$ time units (months). 


\section{Conclusions}

The conclusion which can be reached by considering the results of the research performed on the considered sets of measuring instruments is that the method for estimating the calibration life based on parameter deviation can be used for establishing the appropriate moment for performing the calibration for a specific set of measuring devices. This calibration may be performed at a shorter period than that specified in the appropriate standards, case in which no negative consequences can be generated or it may be possible to be performed at a longer period than that specified in the appropriate standards, case in which is possible to reduce the costs of the operation of calibration. By performing the appropriate program in the case of a set of specific measuring devices, it is possible to test whether the values estimated for the calibration life for each case considered meet the requirements set in the appropriate standards.

The method for estimating the calibration life can be used in the analysis of the metrological reliability, for determining the calibration life of the measuring devices, in order to meet the requirements of the quality assurance in metrology. The method is intended to be applied to other types of metrological devices.

\section{References}

1. Wiener U., Veres F. (1972): Fiabilitatea metrologică. Modele și metode (Metrological reliability. Models and methods). Calitatea produselor şi metrologie (Quality of products and metrology), No. 5, pp. 265-271 (in Romanian)

2. Clinciu R. (2000): Algorithm for the Simulation of Parameter Deviation. Bulletin of the Transilvania University of Brasov, ISSN 1223-9631, Vol. 7(42), pp. 65-68

3. Clinciu R., Clinciu M.R. (2012): Estimating the Calibration life for Measuring Devices. Academic Journal of Manufacturing Engineering, ISSN 1583-7904, No. 10/2, pp. 30-35

4. Clinciu M.R. (2009): Estimating The Statistical Parameters For Data Samples In An Experimental Installation. Proceedings of ModTech 2009, ISSN 2066-3919, pp. 167-170, Iaşi, Romania

5. L.O. - 2012 (2012): Lista oficială a mijloacelor de măsurare supuse controlului metrologic legal (Official list of the measuring instruments which need to be calibrated). Monitorul oficial 361/2012, Bucuresti (in Romanian)

6. Voda V.Gh. (1979): Metode de testare a normalității datelor de măsurare (Methods for testing the normality of the measuring data). Metrologia aplicată (Applied metrology), No. XXVI (1), pp. 11-14 (in Romanian)

7. Martinescu I., Popescu I. (1995): Fiabilitate (Reliability). Gryphon, ISBN 973-604-007-0 (in Romanian)

8. Kececioglu D. (2002): Reliability Engineering Handbook. Prentice Hall, ISBN 978-1-932078-00-8

9. Montgomery D.C. (2003): Applied Statistics and Probability for Engineers. John Wiley \& Sons, ISBN 0-471-20454-4

10. Zio E. (2007): An Introduction to the Basics of Reliability and Risk Analysis. World Scientific, ISBN 978-981-279639-3, https://doi.org/10.1142/6442

11. Morariu C.O. (2014): Statistică aplicată (Applied Statistics). Editura Universităţii Transilvania, ISBN 978-60619-0397-9, Brașov, Romania (in Romanian)

12. Dobrițoiu N. (2018): Ingineria calităţii (Quality Engineering). Universitas Publishing House, ISBN 978-973-741583-7, Petroșani, Romania (in Romanian) 